\title{
Personality Profile of Students' Council: A Comparative Study between Genders
}

\author{
Khaidzir Hj. Ismail ${ }^{1,2}$, Khairil Anwar ${ }^{2,5}$, Shaharuddin Ahmad ${ }^{3}$, Jumali Hj. Selamat ${ }^{1}$ \& Azizan Ahmad ${ }^{1,4}$ \\ ${ }^{1}$ Centre for Learning Accreditation, Universiti Kebangsaan Malaysia, Bangi, Malaysia \\ ${ }^{2}$ School of Psychology and Human Development, Faculty of Social Sciences and Humanities, Universiti \\ Kebangsaan Malaysia, Bangi, Malaysia \\ ${ }^{3}$ Faculty of Social Sciences and Humanities, Universiti Kebangsaan Malaysia, Bangi, Malaysia \\ ${ }^{4}$ Faculty of Science and Technology, Universiti Kebangsaan Malaysia, Bangi, Malaysia \\ ${ }^{5}$ Faculty of Psychology, Universitas Islam Negeri Sultan Syarif Kasim Riau, Indonesia \\ Corresponding: Khaidzir Hj. Ismail, Center for Learning Accreditation, Universiti Kebangsaan Malaysia, 43600 \\ Bangi, Selangor, Malaysia. Tel: 60-3-8921-3147. E-mail: izay@ukm.my
}

Received: January 15, $2013 \quad$ Accepted: February 21, $2013 \quad$ Online Published: March 28, 2013
doi:10.5539/ass.v9n4p77
URL: http://dx.doi.org/10.5539/ass.v9n4p77

\begin{abstract}
This study aims at analyzing students' personality profile of a group of students who attended a basic program $(\mathrm{N}=165)$ that would help them become future student leaders. It also intends to compare the personality profile between male $(\mathrm{N}=103)$ and female $(\mathrm{N}=62)$ subjects. The 16PF personality test was used to analyze the data in this study. The findings show trait 5 of the 16 personality factors that measures leadership qualities i.e. thinking trait, was at stage 4 for both, male and female. This suggests that their thinking skill is still low; emotional stability trait was at stage 5 which points to instability, also, for both genders; dominance trait was at 4 for female and 5 for male which implies that males are more dominant. As for regulation awareness, females had a higher reading compared to the males with the reading of stages 6 and 4 respectively. On the other hand, both male and female are at stage 4 for trust trait which suggests group orientation is favoured over individual. It is hoped that the findings of this study would be used as the basis for developing students' leadership excellence in moving towards more ethics and academics.
\end{abstract}

Keywords: student council, personality, profile, leadership, gender

\section{Introduction}

Leadership is not simply a political issue as it is a discussion that touches on human basic needs to create appropriate interaction polar among individuals, between individuals and groups and between groups. Within this interaction, there is a goup of people who will take more roles than the others in the effort to maintain proper order in the community. According to Ibrahim Mamat (1993), a leader is an individual among a group of people who is given the responsibility to manage and coordinate activities in order to achieve the group's pre-planned objectives. He also feels that being a leader is deep in meaning in which an individual can motivate his followers to work hard to produce something outstanding. The leader does not just assist, manage, or motivate but rather a combination of all three. In whatever activity involving humans, be it in a marriage or in an organization which is more complex up to managing a country, one can never run away from the issue of leadership.

In addition,one of the issues that should be considered is the question of leadership. The responsibility of preparing the future leaders is heavier than getting the basic infrastructure needs of physics-based material ready. This is so because leadership relates to human complexity that needs to be nurtured through education up to becoming an adult. On the other hand, maturity in thinking is developed through certain social process such as in a marriage, school, or within the community. Leadership does not only involved certain knowledge like science and technology, but also a balanced personality and high spiritual awareness that enable one to carry out the function of leadership that is fair and with morals to achieve justice and total well-being. The element of psychology that needs to be developed is personality and leadership. They need to be prepared as future leaders with knowledge of religion, personality, and vision (Zakarija Achmat, 2006; Collins, 2000). 
The country's leadership should not only focus on the issue of political parties alone in the process of producing future leadership. Hogan et al. (1994) explains the views of political scientists that is fundamental to humans is the question "who will lead or rule?" As for that, all activities and programs that lead to the preparation of quality future leader should be fully supported as the most important aspect of leadership is the quality of decision makers. The issue that needs to be given emphasis in preparing students' leadership at university level is the process of developing leadership qualities in which the Student Affairs Body on the university campus is included in the framework.

Actually, there are many aspects that determine the leadership in higher institutions. In general, there are six characteristics of a good leader as pointed out by George (2005) that are honesty and originality, humorous, sensitive towards others' welfare, positive thinking, the desire to be successful and the principle of knowledge first over rules. This feature is very dependent on the personality of the individual who wants to be a leader. For Fiedler (1976), the personality factor in leadership is something very important to note. Unfavorable situation can sometimes lead to effective leadership if approached appropriately or operated by those who have suitable personality for the situation. Task-oriented leader is one who can provide effective leadership in a either most profitable or unprofitable situation. Permissive leaders with interpersonal oriented relationships are more suited to moderate situation (Aminuddin \& Mohd. Ali Kamaruddin, 1988). Hence, leadership ability can be predicted through analysis of personality.

The word 'Personality' is derived from the Latin word 'persona' which means mask. Therefore, personality can refer to observable external characteristics (Wan Ahmad Wan Kader, 2000). It is observed that there are special features, whether good or bad, that make a person. The 'persona' or 'mask' changes over time and eventually brings about meaning to the quality of the individual's internal and external characteristics (Habibah \& Noran Fauziah, 2006). Nevertheless, personality also includes aspects of thinking, perceptions, values, attitudes, character, ability, confidence, intelligence, motivation, habits and so on. According to Mohd Zuri Ghani et. al. (2008), research on personality is important since the general population feels that bright students behave better than normal ones. In reality, however, this might not be true because all the students in the same class have similar good values. The belief that clever students are better can lead to unjust and negative practice in other students. Therefore, every student has equal rights to be respected and to receive proper experience and education.

Personality is considered as a variable that can predict one's leadership in an organization especially students' leadership in higher institutions (compare Meng-long shih et. al. 2009 and Puvarattanakul \& Muenjohn, 2009). Identifying personality trait in potential student leaders is crucial in order to create leaders who are strong and capable of handling increasingly complex challenges in future. In debating about personality, it covers all activities related to mankind and life. This includes relationship between people and the association with the surrounding. For S. Husin Ali (1977), a leader is one who leads others through his ideology and influence in order to achieve the community's objectives and directions. The leader has the right and obligation to help, guide, and lead in line with his status in his community. However, Leadership is a process of how an individual or a leader gains cooperation and help from his followers to achieve an objective (Campbell et. al., 1983). Rubiah (1993), on the other hand, explains the characteristics of renowned leadership that includes honesty, generosity, forgiving, humble, able to take critics, and always respect others' opinions. Hence, to be a leader and to produce future leaders is not an easy task. Instead, it needs high commitments, knowledge and soft-skills to ensure that they are really holistic leaders.

The issue of gender in leadership has often been discussed in the context of socio-culture, socio-psychology as well as socio-religion. Modern education seems to give a wider opportunity to every student, male or female, to become an empowered leader. This study aims at identifying the profile for potential candidates for future leaders based on gender differences. Will there be a difference between male and female candidates for UKM Student Representative Council?

\section{Method}

The study used 16PF personality Test version 5 created by Cattel et.al., 1985. This method is widely used in the fields of health, education and occupation. Throught this test, a comprehensive profile of the student leader candidates that will be the predictor to student leadership polar was created. This study focused on 16 persoanlity traits.

1) Trait A: Intimacy (Quiet- Friendly) Low Score - isolation, critical, unfriendly, calm (Sizothymia). High Score - friendly, sociable, cooperation (Attretothymia)

2) Trait B: Thinking (Concrete - Abstract) Low Score - concrete thinking, less intelligent (Lower Scholastic 
Mental Capacity) High Score - abstract thinking, more intelligent, smart (Higher Scholastic Mental Capacity)

3) Trait C: Emotional Stability (Reactive - Stable) Score Low - emotionally unstable, easily influenced by emotions (Lower Ego Strength) High Score - emotionally stable, easy to deal with reality (Higher Ego Strength)

4) Trait E: Dominant (Co - Dominant) Score Low - Humility, obedience and conformity (Submissivemess) High Score - Assertive, aggressive, stubborn and independent (Dominance)

5) Trait F: highly spirited (Serious - Joyful) Low Score - sound, serious, cautious (Desurgency) High Score less serious, joyful, enthusiastic (Surgency).

6) Trait G: Awareness of Regulation (Non Compliant - Compliant) Low Score - Casual, not firm, do not comply with regulation (Weaker superego Strength) High Score - Cautious, strong, calm, polite (superego Stronger Strength)

7) Trait H: Social Courage (Reluctance - Bravery) Low Score - Shy, gentle (Threctia) High Score - courageous, spontaneous, assertive (Parmia)

8) Trait I: Sensitivity (objective - Sensitivity) Score Low - Tough mind, realistic (Harria) High Score - Sensitive, gentle, dependent, not realistic (Premsia)

9) Trait L: Awareness (Accepting - Alert) Score Low - Honest, reliable, adapt easily (Alaxia) High Score Suspicious, not easily cheated, full of suspicous (Pretension)

10) Trait M: preoccupied Thinking (Practical - Imaginative) Low Score - Practical, conventional, cautious (Praxemia) High Score - Imaginative, less conventional (Autia)

11) Trait N: Secrecy (Open-careful) Score Low - Sentimental, natural, honest (Artlesness) High Score sophisticated, sharp mind, clever (Shrewdnes)

12) Trait O: Concerned (Quiet - Aid) Score Low - Confident, calm, peaceful (Untrouble dequacy High Score anxious, worried, depressed (Guilt Proneness)

13) Trait Q1: Open to Changes (Traditional - Open) Score Low - Conservative, Traditional (Conservatism) High Score - Liberal., Critical (Radicalism)

14) Trait Q2: Self Belief (Group - individualistic) Low Score - Group, orientation to group (Group Adherence) High Score - Independent, fond of making decisions (Self-sufficiency)

15) Trait Q3: Orderliness (Tolerance - Discipline) Low Score - self desired, casual (Low Integration) High Score - Controlled, self-discipline, compulsive (High Self-Control Concept)

16) Trait Q4: Tension (Relax - Stiff) Low Score - Calm, serene (Low Ergic tension) High Score - Tense, worry, anxiety (Ergic High tension)

(Source profiles by Wan Ahmad Wan Kader, 2000).

Research subjects consisted of 165, with 103 males and 62 females, prospective candidates of Universiti Kebangsaan Malaysia (UKM). Statistical Analysis $t$ test was used to look at the personality differences between genders. The result were presented in descriptive and inferential statistical analysis.

\section{Results and Discussions}

Table 1 shows the distribution of potential candidates for UKM Students' Representative Council. They were from various backgrounds representing different faculties, programs, courses, residential colleges, associations and others. They represent a small part of UKM students consisting of 103 or $62.42 \%$ male students and 62 or $37.58 \%$ female students. The results showed that the total distribution of subjects between boys and women were disproportionate. This could be due to the natural human instinct whereby males are more inclined to become leaders.

Table 1. Distribution according to gender

\begin{tabular}{ccc}
\hline Gender & $\mathbf{N}$ & $\mathbf{( \% )}$ \\
\hline Male & 103 & 62.42 \\
Female & 62 & 37.58 \\
Total & 165 & 100 \\
\hline
\end{tabular}


Table 2 shows the comparative analysis of respondents' trait personality. Using the t-test statistical analysis, trait G shows awareness on rules $(t=-2788, k<0.05)$, for trait $\mathrm{I}$, it shows sensitivity trait $(\mathrm{t}=-2493, \mathrm{k}<0.05)$, trait $\mathrm{L}$ displays level of awareness $(t=2016, \mathrm{k}<0.05)$, trait Q2 shows self-belief $(\mathrm{t}=2162, \mathrm{k}<0.05)$ and in trait Q3 presents attitudes of orderliness $(\mathrm{t}=-2186, \mathrm{k}<0.05)$. Whereas in the trait $\mathrm{A}$ (affection), trait $\mathrm{B}$ (thinking), trait $\mathrm{C}$ (emotional stability), trait $\mathrm{E}$ (dominance), trait $\mathrm{F}$ (enthusiasm), trait $\mathrm{H}$ (Social boldness), trait $\mathrm{M}$ (preoccupied in thinking), trait $\mathrm{N}$ (confidentiality), trait $\mathrm{O}$ (anxiety), Q1 (readiness to change) and Q4 (tension) display no significant difference between male and female students.

Furthermore, the findings presented a comparison between both male and female potential candidates' personality traits using the t-test. Through this research, statistical analysis showed a difference in personality trait $\mathrm{G}$ showing awareness on rules. It showed that prospective female are more organized than the males with a mean (15.74) and (14:15) respectively. This finding suggests that female students are more compliant than the males. Most often the feminine nature in females displays seriousness in every activity performed by women while men are seen as more aggressive than women. In addition, it appears that women are more serious at work than men. As for 'satisfaction', men sometimes get it from violation of rules, whilst women are more satisfied obeying rules.

Trait 1 showed some difference in sensitivity between male and female students. This difference was reflected in the mean for female students (11.92) which was higher than the mean for males (10:34). Thus, this suggests that female students are more sensitive than males. This advocates that women have more aesthetic properties than men have. As such, women are able to give to more love to someone compare to men. Sometimes female leaders are more aware than male but they are more sensitive that would weaken their leadership.

Table 2. Comparative trait personality between gender

\begin{tabular}{|c|c|c|c|c|c|c|}
\hline Factor & Gender & $\mathrm{N}$ & $\mathrm{df}$ & Mean & SD & $\mathrm{t}$ \\
\hline \multirow[t]{2}{*}{ Trait A } & Male & 103 & 163 & 15.34 & 3.46 & -.386 \\
\hline & Female & 62 & & 15.60 & 3.61 & \\
\hline \multirow[t]{2}{*}{ Trait B } & Male & 103 & 163 & 7.09 & 2.14 & -.306 \\
\hline & Female & 62 & & 7.19 & 2.20 & \\
\hline \multirow[t]{2}{*}{ Trait C } & Male & 103 & 163 & 12.38 & 3.54 & -.080 \\
\hline & Female & 62 & & 12.42 & 4.27 & \\
\hline \multirow[t]{2}{*}{ Trait E } & Male & 103 & 163 & 10.64 & 2.90 & -1.676 \\
\hline & Female & 62 & & 11.45 & 3.19 & \\
\hline \multirow[t]{2}{*}{ Trait F } & Male & 103 & 163 & 11.23 & 3.68 & .808 \\
\hline & Female & 62 & & 10.78 & 3.28 & \\
\hline \multirow[t]{2}{*}{ Trait G } & Male & 103 & 163 & 14.15 & 3.89 & $-2.788^{*}$ \\
\hline & Female & 62 & & 15.74 & 2.86 & \\
\hline \multirow[t]{2}{*}{ Trait H } & Male & 103 & 163 & 11.09 & 4.53 & -.613 \\
\hline & Female & 62 & & 11.55 & 4.66 & \\
\hline \multirow[t]{2}{*}{ Trait I } & Male & 103 & 163 & 10.34 & 4.01 & $-2.493^{*}$ \\
\hline & Female & 62 & & 11.92 & 3.83 & \\
\hline \multirow[t]{2}{*}{ Trait L } & Male & 103 & 163 & 12.25 & 3.01 & $2.016^{*}$ \\
\hline & Female & 62 & & 11.26 & 3.17 & \\
\hline \multirow[t]{2}{*}{ Trait M } & Male & 103 & 163 & 9.19 & 4.14 & 1.114 \\
\hline & Female & 62 & & 8.45 & 4.16 & \\
\hline \multirow[t]{2}{*}{ Trait N } & Male & 103 & 163 & 12.20 & 3.63 & .376 \\
\hline & Female & 62 & & 11.98 & 3.64 & \\
\hline \multirow[t]{2}{*}{ Trait O } & Male & 103 & 163 & 12.88 & 3.36 & .273 \\
\hline & Female & 62 & & 12.74 & 3.00 & \\
\hline
\end{tabular}




$\begin{array}{cllllll}\text { Trait Q1 } & \text { Male } & 103 & 163 & 18.70 & 4.10 & -.881 \\ & \text { Female } & 62 & & 19.29 & 4.30 & \\ \text { Trait Q2 } & \text { Male } & 103 & 163 & 5.83 & 4.45 & 2.162^{*} \\ & \text { Female } & 62 & & 4.37 & 3.70 & \\ \text { Trait Q3 } & \text { Male } & 103 & 163 & 13.65 & 3.70 & -2.186^{*} \\ & \text { Female } & 62 & & 14.85 & 2.93 & \\ \text { Trait Q4 } & \text { Male } & 103 & 163 & 7.59 & 3.54 & .668 \\ & \text { Female } & 62 & & 7.17 & 4.35 & \\ & & & & & & \end{array}$

$\mathrm{k}^{*}<0.05$

Trait L presents vigilance personality. Studies have shown a slight difference between male and female students. The mean for males (12:25) was higher than the mean for female students $(11: 26)$. Thus, males are more uspicious than females. In the context of leadership men make more foes as well as create rivalry than women.

Next, trait Q2, which is self belief personality, also saw a difference between male and female students. The mean is for male candidates (5.83) is higher than the females (4.37). This analysis indicates that men are more individualistic than women. The ladies are also more team-oriented. This finding is consistent with the individualistic characteristics that often appear in aggressive behavior. However, in many cases, men are more aggressive than women.

Interesting findings can also be seen from the differences in Q3 reflecting orderliness trait. The analysis found that the mean for female (14.85) was higher than that of the males (13.65). This difference shows women are more organized and manageable compared to men.

Table 3 shows the personality profile by gender. It was found that there were six dominant traits which showed some differences between the prospect male and female candidates which were traits A, E, G, I, L and N, while the other traits were at the same level. Trait A displays the level of intimacy for males and it was located ideally in stage 6 whereas the female students were at stage 5. For this factor the level of affection for each prospective candidate must be from stages 6 to 10. This distinction shows that male students are friendlier than the females. This implies that in oerder to become successful leaders friendly attitude crucial to ensure that the supporters and followers are loyal and stick together in whatever situation faced.

Table 3. Comparative personality profile between gender

\begin{tabular}{ccc}
\hline Trait & Male & Female \\
\hline A & $\mathbf{6}$ & $\mathbf{5}$ \\
B & 4 & 4 \\
C & 5 & 5 \\
E & $\mathbf{4}$ & $\mathbf{5}$ \\
F & 5 & 5 \\
G & $\mathbf{5}$ & $\mathbf{6}$ \\
H & 6 & 6 \\
I & $\mathbf{6}$ & $\mathbf{4}$ \\
L & $\mathbf{6}$ & $\mathbf{5}$ \\
M & 6 & 6 \\
N & $\mathbf{6}$ & $\mathbf{5}$ \\
O & 5 & 5 \\
Q1 & 6 & 6 \\
Q2 & 4 & 4 \\
Q3 & 6 & 6 \\
Q4 & 4 & 4 \\
\hline
\end{tabular}


The score for trait $\mathrm{E}$ indicates a dominant personality pattern in which female students are at stage 5 that is ideal for aspiring candidates. Whilst, the men are at stage 4 which is less than ideal. For this trait, the ideal score required is between stages 5 to 7 . This indicates that a leader must have a trait located in between 'dominant and co-operation'. However, leaders must have medium dominance trait to present character strength that is not easily shaken when facing a lot of questions and problems. At stage 7, it is still considered medium dominance that allows working in a variety of conditions within their group.

Score on trait $\mathrm{G}$ reflects the awareness of regulations. For this trait, every leader is required to be at stsges 6 to 10 that is the ideal scale. This required score limitation reflects the personality of an ideal leader who is able to follow rules in carrying out his leadership responsibilities in the organization. The results indicated that female students are at 6 and men at stage 5. Hence, female students showed higher levels of awareness on rules than the male counterparts.

Trait I describes the sensitive personality of a person with the ideal stage at 5 to 6 of which it means the sensitivity must be balanced between the objective and aesthetic. The ideal leader must be objective in nature and not be too emotional. Nevertheless, a leader should possess sensitivity, aesthetics and have feelings in carrying out the responsibilities for a leader cannot be too rigid and confined at establishing regulations as stipulated. A leader must have a clean conscience and able to compromise with certain circumstances that requires decisions to be made against the rules for humanity sake based on love. For this trait, the males were at stage 6 and women at 4 . It can be concluded that the potential females' leadership objectives is higher than male student. However, for males who were at stage 6 are more ideal as candidates they showed a more balanced state between objective and aesthetic.

Next, trait L showed the cautiousness personality for a leader is idea at stages 4 to 5 . This is moderate and balanced between full trust, unsuspicious, and acceptance against cautious, suspicious and awareness. However, leadership is more anticipated to be at the moderate stage as it can give appreciation and recognition on certain beliefs by his subordinates. Imagine if the leader has too high of cautiousness level, it will lead to feelings of distrust and suspicion. Consequently, more of other people's responsibilities would be taken over by the leader as he does not trust others. Stage 4 reflects moderately good attitude. When a leader is at stage 3 and below, there is a tendency for fraud and betrayal to occur in the organization. The study found the profile for potential female candidates at stage 5 and the males at 6 . Hence, female students are at the ideal stage while the boys stood at less ideal for scoring moderately high at suspicion and mistrust.

For $\mathrm{N}$ trait, it shows the personality pattern of secrecy with stage 5 to 6 is ideal for a potential candidate. Low stage at this trait demonstrates honesty, unpretentious, weak at winning hearts. On the contrary, high stage reflects strongly secretive, cautious, and refusal to tell. Both the above continuums show the polar of extreme personality at either low or high stage. A leader should be at the moderate stage at which a leader should know how to be honest or otherwise. In this case, leaders should be able to have diplomacy when revealing a problem. Imagine a leader reveals the country's secrets to someone just for the sake of being honest and then, imagine a leader who instantly scolds an author in front of other playrights. In constrast, a leader who is too secretive and reluctant to tell, will be a leader who does not have an open soul to convey information that should be known by the public. This polar brings about the attitudes of nepotism and cronyism. For this trait, female students' profile was at stage 5 and males at 6 . Therefore, female students are more truthful than males. However, both male and female students are at the moderate stage which is appropriate for potential candidates.

In addition, this study also touched on the visibly dominant trait as in traits B, C, and Q2 but the both genders were at the same stage. For instance, for trait B, both male and female students were at the same stage 4 which suggests that the thinking level is not ideal or the mindset is still low to become a leader. This condition occurs due to immature development and premature development that takes place at the end of adolescence. Meanwhile, trait $\mathrm{C}$ displays emotional stability of both male and female students were at the same level i.e. stage 5 . This stage presents is not ideal for leaders as it to shows emotional instability or emotional reaction when faced with certain situations. Nevertheless, this stage shows moderate level of reactive.

Finally, Q2 displays self belief. The ideal stage for this trait should be at 6 to 7 . This means a leader should possess a little bit of group orientation but it should satisfy the attitude of self trust in order to perform a particular task. However, this trait is restricted to stages 6 to 7 as it still reflects the balance between the group's needs and self-confidence. At stage 8 for this trait, leaders are more inclined to show individualistic nature that will produce leaders who are autocratic. This study found that both male and female students were at the same level i.e at stage 4 , suggesting that the situation is not ideal for a leader. The low performance on this trait shows 
the inability of one to escape from group control or in other words, it is highly dependent on the group's decision. However, leaders are expected to possess the strength to solve a problem as part of his responsibility.

\section{Conclusion}

This study is an effort to identify more closely the personality characteristics of potential leader candidates among the UKM students. The facts in this research implies that leadership is not owned by a particular person or a particular gender. It is rather a question of leadership potentials. It is seldom seen the females having more leadership spirit than males. This phenomenon is not impossible as it is happening on the campus of the University Kebangsaan Malaysia. This means the role of the campus to provide knowledge and sharpens the minds is actually taking place. Both men and women have equal rights to education. At present, a lot of transformations are taking place and it is not impossible that one day females will surpass the males' leadership. This is because women are more diligent, hardworking and they dutifully follow the learning process at the learning institutions.

\section{References}

Achmat, Z. (2006). Effectiveness of personality and leadership training in self believe among new students of UMM intake 2005/2006. Humanity, 1(2), 117-121.

Ahmad, W. A. K. W. (2000). Personality Profile as a basic changes in an organization's personalities trait. Journal PERKAMA, 8, 101-136.

Ali, S. H. (1977). Community and village leaders in Malaysia. Kuala Lumpur: Publisher Fajar Bakti.

Campbell, R. E., Corball, J. E., \& Nystrand, R. O. (1983). Introduction to educational administration (6th ed.). Boston: Allyn and Bacon.

Cattel, R. B., Eber, H. W., \& Tatsuoka, M. M. (1985). Sixteen personality factor questionaire (16 PF). Illionis, Institute For Personality and Ability Testing, Inc.

Collins, M. (2000). Personality and political leadership explored: Richard Nixon and the family assistance plan. Faculty of the Virginia Polytechnic Institute and State University.

Fiedler, F. E. (1976). Improving leadership effectiveness the leader match concept. New York: Wiley.

George, M. D. (2005). Personal Characteristics of Leaders, What works, what matters, what lasts (Vol. IV). Retrieved July 20, 2010, from http://www.pkal.org/page.cfm?page=4158

Hamzah, R. K. (1993). Adolescence and leadership organization. Kuala Lumpur: Dewan Bahasa dan Pustaka.

Hogan, R., Curphy, G. J., \& Hogan, J. (1994, June). What We Know about Leadership: Effectiveness and Personality. American psychologist, 1-33.

Mamat, I. (1993). School leadership: theory and practice. Kuala Lumpur: Kumpulan Budiman.

Mohd et al. (2008). Personality differences for extrovert and introvert among gifted students according to gender. Jurnal Pendidik dan Pendidikan, 23, 111-122.

Puvarattanakul, S., \& Muenjohn, N. (2009). Leadership personality traits and satisfaction, Effectiveness and productivity. International conference on business and information (BAI), 5(1).

Shih, M. L. (2009). The study of the correlation among personality traits, leadership competence and organizational performance. wseas transactions on business and economics, 6(1), 11-20.

Yusof, A. M., \& Kamarudin, M. A. (1988). Leadership of UMNO's Youth: Between personality and situation. Bangi: Penerbit Universiti Kebangsaan Malaysia. 